\title{
On the functional group tolerance of ester hydrogenation and polyester depolymerisation catalysed by ruthenium complexes of tridentate amino-phosphine ligands.
}

José A. Fuentes, ${ }^{[\mathrm{a}]}$ Samuel M. Smith, ${ }^{[\mathrm{a}]}$ M. Theresa Scharbert,,${ }^{[\mathrm{a}]}$ Ian Carpenter, ${ }^{[\mathrm{a}]}$ David B. Cordes, ${ }^{[\mathrm{a}]}$ Alexandra M. Z. Slawin, ${ }^{[\mathrm{a}]}$ and Matthew L Clarke ${ }^{\star[a]}$

School of Chemistry, University of St Andrews EaStCHEM, St. Andrews, Fife, KY16 9ST (UK) Fax: (+44)1334-463808

E-mail: mc28@st-andrews.ac.uk

\begin{abstract}
The synthesis of a range of phosphine-diamine, phosphine-amino-alcohol, and phosphineamino-amide ligands and their ruthenium(II) complexes are reported. Five of these were characterised by X-ray crystallography. The activity of this collection of catalysts was initially compared for the hydrogenation of two model ester hydrogenations. Turnover frequencies up to $2400 \mathrm{~h}^{-1}$ were observed at $85{ }^{\circ} \mathrm{C}$. The catalysts turnover, albeit slowly at near ambient temperatures. Using a phosphine diamine $\mathrm{Ru}(\mathrm{II})$ complex that was identified as the most active catalyst, a range of aromatic esters were reduced in high yield. The hydrogenation of alkene-, diene-, and alkyne functionalised esters was also studied. Substrates with a remote, but reactive terminal alkene substitutent could be reduced chemoselectively in the presence of 4-dimethylaminopyridine (DMAP) co-catalyst. The chemoselective reduction of the ester function in conjugated dienoate ethyl sorbate could deliver (2E,4E)-hexa-2,4-dien-1-ol, a precursor to leaf alcohol. The mono-unsaturated alcohol $(E)$-hex-4-en-1ol was produced with reasonable selectivity, but complete chemoselectivity of $\mathrm{C}=\mathrm{O}$ over the diene is elusive. High chemoselectivity for the reduction of an ester over an alkyne group was observed in the hydrogenation of an alkynoate for the first time. The catalysts were also active in the depolymerisation reduction of samples of waste PET to produce benzene dimethanol. These depolymerisations were found to be poisoned by the ethylene glycol side product, although good yields could still be achieved.
\end{abstract}


The catalytic reduction of esters to alcohols using molecular hydrogen can be considered an attractive method relative to the use of stoichiometric reducing agents. Improved atom economy, reduced cost, and safer, easier product isolation are key advantages. Heterogeneous metal surface catalysts can accomplish this task rather well, but generally at high pressures. ${ }^{[1]}$ Moreover, many useful functional groups such as alkene, halide, ketone, benzyl, and sometimes even phenyl groups are hydrogenated under typical ester hydrogenation conditions. Homogeneous catalytic ester hydrogenation has been put forward as a potentially valuable reaction that could be chemoselective and operate under mild conditions. ${ }^{[2,4]}$ For a long time and until quite recently, this was just a possibility, ${ }^{[4]}$ but in recent years ester hydrogenation has come of age. ${ }^{[5]} \mathrm{A}$ variety of catalysts have now given encouraging results. Our interest in this reaction started around ten years ago with a study of the chiral phosphine-diamine catalyst $\mathbf{1}$. However, fairly moderate results were observed for ester hydrogenation using procedures that we had optimised for enantioselective ketone reduction using this catalyst. ${ }^{[6(a)]}$ More recently, noticing the tendency for more modern ester hydrogenation catalysts to need rather large base/catalysts ratios, we communicated the use of achiral catalyst $\mathbf{4}$, which can reduce aromatic esters at near ambient temperatures, providing base:catalyst ratios of 30 to 50 are employed. ${ }^{[7]}$ Here we give a full account of this work, including comparisons to other related ligand systems. We also now address the unresolved question of the relative rates of reduction of esters, alkene, diene and alkyne functional groups, and study the depolymerisation of a polyester.

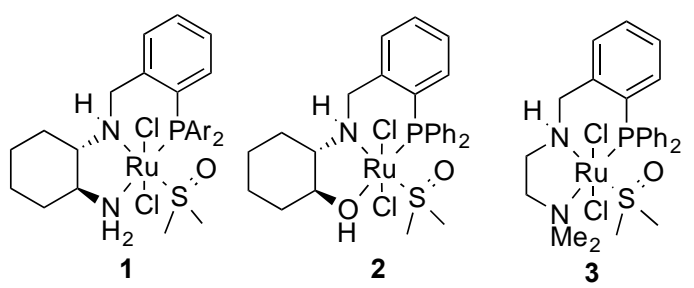

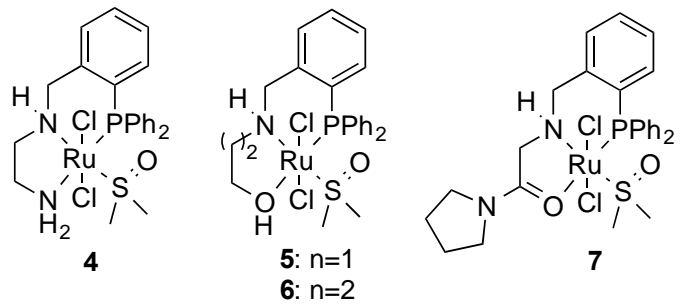

Figure 1. Ruthenium complexes of phosphine-diamine, phosphine-amino-alcohol and phosphine-amino-amide ligands used in this study.

\section{Results and Discussion}

The chiral ketone hydrogenation catalysts 1, 2 and achiral 3 were prepared as described before; ;[] $^{\left[{ }^{6}\right.}$ an optimised synthesis of $\mathbf{2}$ and $\mathbf{4}$ at multi-gram scale is archived in the experimental section (E.S.I). The synthesis of new Ru complexes 5-7 is also described. The crystal structure of 2 has now been solved and is shown in Fig. 2. While the formula has always been clear from the NMR, MS and microanalytical data, this structure confirms several aspects that were not known. The structure shows the meridional coordination of the $P, N, \mathrm{O}$ ligand. The DMSO ligand is coordinating through sulfur, rather than oxygen, and the chlorides adopt mutually trans orientations. The phosphine amino-alcohol is in a neutral coordination mode with the nitrogen atom becoming chiral at $\mathrm{N}$ on coordination to $\mathrm{Ru}$. In many ways this structure is similar to the structure of 1 that we previously reported. ${ }^{[6(a)]}$ 


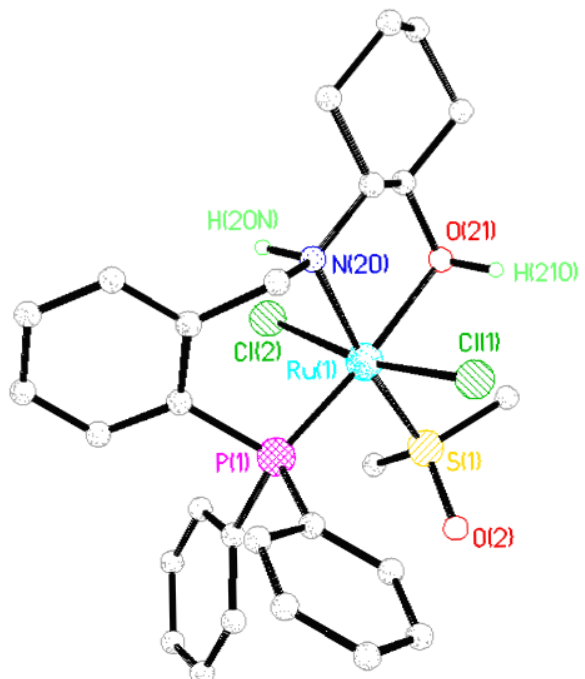

Figure 2. X-ray structure of complex 2. Two acetonitrile molecules and hydrogen atoms (except $\mathrm{NH}$ and $\mathrm{OH}$ ) are omitted for clarity. Selected bond lengths $(\AA)$ and bond angles $(\mathrm{deg})$ : $\mathrm{Ru}-\mathrm{P}(1)=2.256(1), \mathrm{Ru}-\mathrm{N}(20)=2.151(5), \mathrm{Ru}-\mathrm{O}(21)=2.205(3), \mathrm{O}(21)-\mathrm{Ru}-\mathrm{P}(1)=171.31(9), \mathrm{N}(20)-\mathrm{Ru}-\mathrm{P}(1)$ $=92.3(1), \mathrm{N}(20)-\mathrm{Ru}-\mathrm{O}(21)=79.2(1)$.

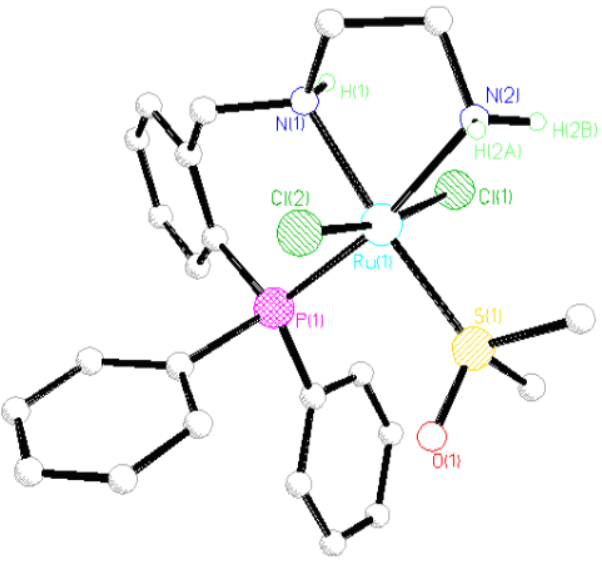

Figure 3. X-ray structure of complex 4. One molecule of acetonitrile and hydrogen atoms (except $\mathrm{NH}$ and $\mathrm{NH}$ ) are omitted for clarity. Selected bond lengths $(\AA)$ and bond angles (deg): $R u-P(1)=2.2806(7), R u-N(1)=2.130(2), R u-N(2)=2.164(2), N(2)-R u-P(1)=170.84(6), N(1)-R u-P(1)$ $=91.10(5), \mathrm{N}(1)-\mathrm{Ru}-\mathrm{N}(2)=79.89(7)$ 


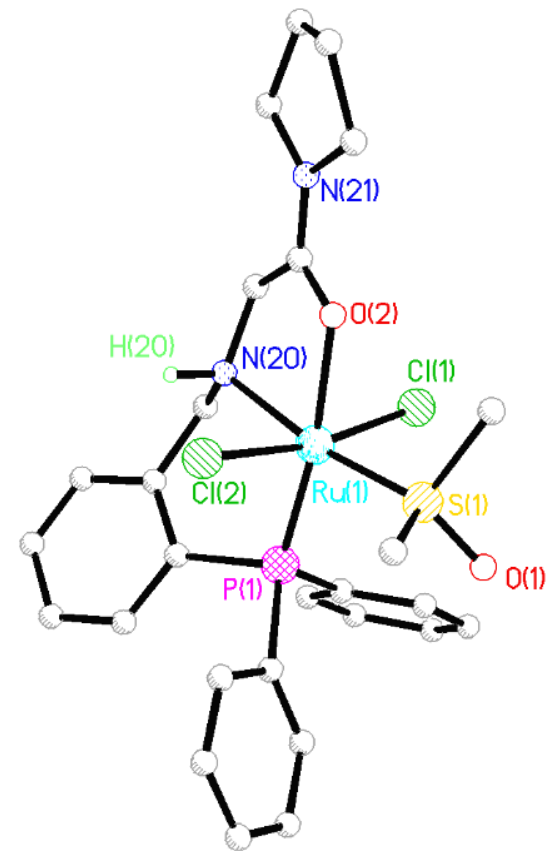

Figure 4. X-ray structure of complex 7. Hydrogen atoms (except $\mathrm{NH}$ ) are omitted for clarity. Selected bond lengths $(\AA)$ and bond angles (deg): $\mathrm{Ru}-\mathrm{P}(1)=2.254(1), \mathrm{Ru}-\mathrm{N}(20)=2.152(4), \mathrm{Ru}-\mathrm{O}(2)=2.156(3), \mathrm{O}(2)-\mathrm{Ru}-\mathrm{P}(1)=170.66(9), \mathrm{N}(20)-\mathrm{Ru}-\mathrm{P}(1)=93.4(1), \mathrm{N}(20)-\mathrm{Ru}-\mathrm{O}(2)=77.2(1)$.

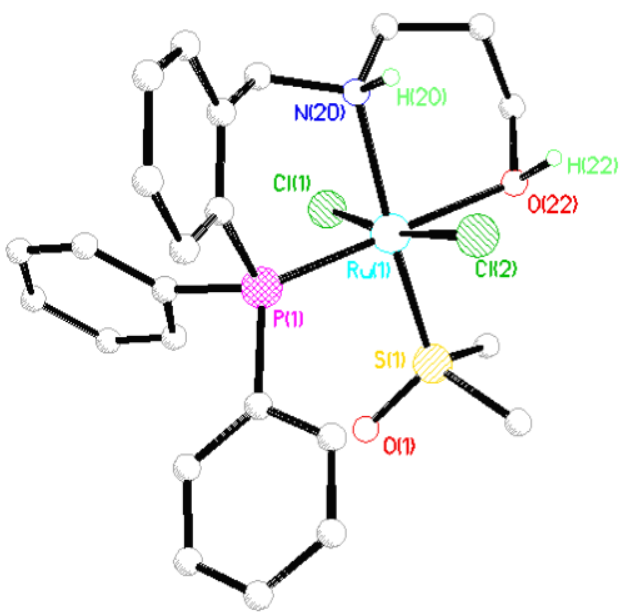

Figure 5. X-ray structure of complex 6. Hydrogen atoms (except $\mathrm{NH}$ and $\mathrm{OH}$ ) are omitted for clarity. Selected bond lengths $(\AA)$ and bond angles $(\mathrm{deg}): \mathrm{Ru}-\mathrm{P}(1)=2.254(1), \mathrm{Ru}-\mathrm{N}(20)=2.200(4), \mathrm{Ru}-\mathrm{O}(22)=2.188(3), \mathrm{O}(22)-\mathrm{Ru}-\mathrm{P}(1)=175.5(1), \mathrm{N}(20)-\mathrm{Ru}-\mathrm{P}(1)=92.1(1), \mathrm{N}(20)-\mathrm{Ru}-\mathrm{O}(22)=$ 87.2(1).

The synthesis of the achiral ethylene diamine derived catalyst 4 is described in the experimental section (E.S.I) and works well providing the optimised procedure is followed. This was characterised by X-ray crystallography (Fig. 3). This complex has a rather similar structure to the phosphine amino-alcohol complex 2; a similar meridional neutral coordination mode, sulfur bound DMSO ligand, trans chloride ligands are all observed. Ru(II) complex 7 and its ligand precursor, are, to the best of our knowledge, new species and can also be synthesised conveniently at multigram scale (E.S.I). This ligand was explored since it has a very low steric demand around the amide oxygen, but this terminus also cannot be readily deprotonated or form hydrogen bonds under the reaction conditions. The $\mathrm{Ru}(\mathrm{II})$ complex was also structurally characterised (Fig. 4.). As expected this is a PNO donor ligand that prefers a meridional coordination. The relative orientation and coordination mode of the chloride and DMSO ligands is as discussed above. The nitrogen of the amide is, as expected, planar as clearly indicated by the short $\mathrm{Csp}^{2}-\mathrm{Nsp}^{2}$ bond length of $1.326(7) \AA$ and the $\mathrm{N}-\mathrm{C}-\mathrm{O}$ angle (120.6(4) deg.). With this series of complexes and the previously published structure of $1,{ }^{[6(a)]}$ it can be seen that the longer Ru-P bond lengths across the series correspond to PNN complexes 1 and 4, 2.2912 (13) and 2.2806(7) $\AA$ respectively. The PN-alcohol complexes 2 and 6 and PN-amido complex 7 all have shorter Ru-P bonds due to the fact that the amide and alcohol are weaker trans labilising ligands. In PN-amido complex 7, binding via a $\mathrm{sp}^{2}$ oxygen, the 
Ru-O bond is shorter, 2.156(3) $\AA$, in comparison to complexes 2 and 6, 2.205(3) and 2.188(3) Å respectively. Geometry around the metal centre exerts an important effect in catalysis. The PNN and PNO ligands used in complexes 1-5 and 7 are chelating the $\mathrm{Ru}$ centre via a $\mathrm{P}$ atom and the $\mathrm{N}$ or the $\mathrm{O}$ atoms, thus forming one 6 -membered and one 5-membered chelate ring. Complex 6, with two 6-membered chelate rings, was prepared in order to study the effect of increasing the size of the chelate ring of the pre-catalyst in the ester hydrogenation reaction. Ru complex 6 and its ligand precursor are, to the best of our knowledge, new species (full details in the E.S.I.). N-Ru-O angle on complex 6 was, as expected, the largest, 87.2(1) deg., followed by PNO complex 2 (79.2(1) deg.) and amido complex 7 with an angle of 77.2(1) deg. The $\mathrm{N}-\mathrm{Ru}-\mathrm{N}$ angle in PNN complex 4 (79.89(7) deg) was very similar to the $\mathrm{N}-\mathrm{Ru}-\mathrm{O}$ angle in 2 (79.2(1)).

With a range of pre-catalysts in hand, it was felt that some useful information on catalyst design could be obtained from testing this family in the catalytic hydrogenation of esters. Our initial screening methodology used a simple aromatic ester, para-fluorobenzoic acid methyl ester $\mathbf{8}$ as substrate (Table 1). In order to compare the performance of catalysts under similar conditions, several small reactor vials were placed inside larger pressure vessels. It can be seen that each of these stirs to the same extent and will be under the same pressure and heat. These conditions are suited to comparing a single variable, keeping other conditions constant, and have been used in many other studies in our group. These are not necessarily optimised conditions in terms of turnover or minimising pressures; gas mixing relative to a large vessel with direct stirring will not be as effective, hence the use of 50 bar pressure to minimise mass transport problems. Catalysts 1-7 were initially examined at $65^{\circ} \mathrm{C}$ for just 2 hours using base: catalyst ratios of $50: 1$ (entries 1-7).

Table 1. Hydrogenation of para-fluorobenzoic acid methyl ester using $\left[\mathrm{RuCl}_{2}\left(\mathrm{P}^{\wedge} \mathrm{N}^{\wedge} \mathrm{X}\right)(\mathrm{DMSO})\right]$ complexes as pre-catalysts.

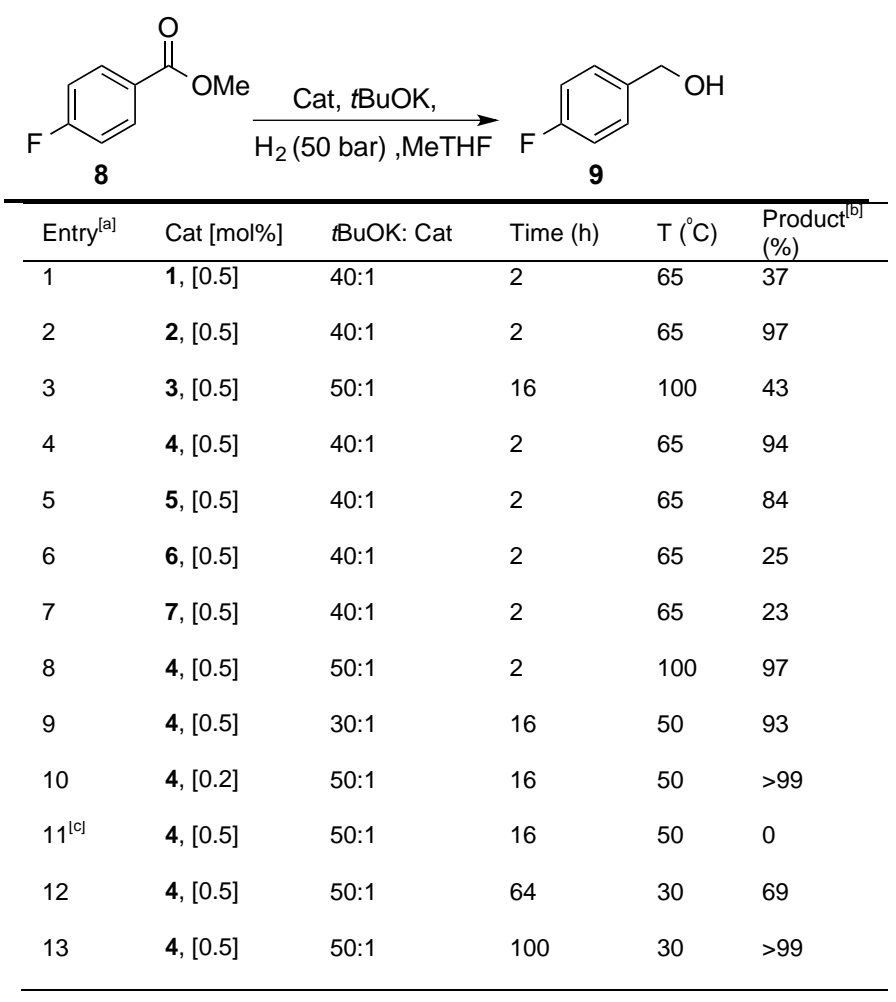

[a] Unless otherwise stated, the reactions were carried out using $0.5 \mathrm{~mol} \%$ $\left[\mathrm{RuCl}_{2}\left(\mathrm{P}^{\wedge} \mathrm{N}^{\wedge} \mathrm{X}\right)(\mathrm{DMSO})\right]$, $\mathrm{BuOK}$ as base $\left(50: 1\right.$, base:catalyst) at $100^{\circ} \mathrm{C}$ at an initial pressure of 50 bar using $0.4 \mathrm{mmol}$ of para-fluorobenzoic acid methyl ester in $3 \mathrm{ml}$ of Me-THF. [b] Conversion determined by ${ }^{19} \mathrm{~F}$ NMR. [c] Use of $\mathrm{KOH}$ or $\mathrm{MeONa}$ as base gives no conversion.

Catalyst 3 was tested at $100{ }^{\circ} \mathrm{C}$ initially and not tested further due to its low activity (entry 3 ). The new catalysts $5-7$ were then benchmarked in the ester hydrogenation reaction (entries 5 to 7). PNO Complex 7 proved to be a poor catalyst under the reaction conditions employed (entry 7), but the achiral PNO complex 5, structurally similar to complex $\mathbf{4}$, achieved good levels of activity (entry 5). Increasing the size of the chelate ring as in complex 6 proved to be detrimental to the activity of the complex in the ester hydrogenation reaction (entry 6 versus entry 5). This type of reactivity has been observed in transfer hydrogenation. ${ }^{[8]}$ Complexes $\mathbf{2}$ and $\mathbf{4}$ showed the highest level of activity, achieving near full conversion within 2 hours. Reaction conditions were next studied using relatively cheap achiral catalyst 4 (entries 8-13). Catalyst loadings down to $0.2 \mathrm{~mol} \%$ (entry 10) and base : catalyst ratios down to 30:1 (entry 9) could be used allowing 
the reduction of aryl esters at temperatures from $100 \stackrel{\circ}{\circ}$ to as low as $30 \stackrel{\circ}{C}$ (entry 14). Catalyst 4 was used in the hydrogenation of other aromatic esters with different electronic properties (Table 2). Noteworthy is the fact that 3-pyridyl ester 16 could be successfully hydrogenated but not 2-pyridyl, and 2-pyrrolyl esters (entries 8 and 9). A possible explanation for this fact is the ability of both ester and alcohol of the corresponding compounds to function as a bidentate $\mathrm{N}, \mathrm{O}$ ligand for Ru and inhibiting catalysis. Two reactions were set up in which the hydrogenation of ester 8 was carried out ( $50 \stackrel{\circ}{\circ}, 50$ bar $\mathrm{H}_{2}, 0.5$ mol\% cat, $25 \%$ base) in the presence of 20 mol\% of either ester 17 or 2 -pyridyl- $\mathrm{CH}_{2} \mathrm{OH}$. The reactions only gave 23 and $9 \%$ conversions respectively compared to full conversion without these additives. This is therefore consistent with substrate and especially the product acting as an inhibitor.

Table 2. Hydrogenation of various methyl esters using catalyst 6
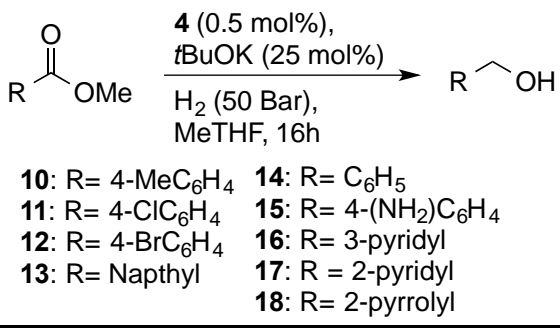

\begin{tabular}{llll}
\hline Entry ${ }^{[\text {[a] }}$ & Ester & $\begin{array}{l}\text { Temp. } \\
\left({ }^{\circ} \mathrm{C}\right)\end{array}$ & $\begin{array}{l}\text { Product } \\
(\%)^{[\mathrm{c}]}\end{array}$ \\
\hline 1 & 10 & 50 & $>99$ \\
2 & 11 & 50 & $>99$ \\
3 & 12 & 50 & $>99$ \\
4 & 13 & 50 & $>99$ \\
5 & 14 & 50 & $>99$ \\
6 & 15 & 100 & 0 \\
7 & 16 & 100 & $>99$ \\
8 & $\mathbf{1 7}$ & 100 & 0 \\
9 & 18 & 100 & 0 \\
\hline
\end{tabular}

[a] Unless otherwise stated, the reactions were carried out using $0.5 \mathrm{~mol} \%$ of cat, $t$ BuOK as base $25 \mathrm{~mol} \%$, (50:1, base:catalyst) at an initial pressure of 50 bar using $0.4 \mathrm{mmol}$ of ester in $3 \mathrm{ml}$ of Me-THF. [b] Conversion determined by ${ }^{1} \mathrm{H}$ NMR.

Next we examined the catalytic activity of the PNN and PNO Ru complexes for the hydrogenation of ethyl acetate (Table 3). Initially, and in order to compare performance of catalysts under the same conditions, several small reactor vials were placed inside larger pressure vessels (Table 3, entries 1-5). Under 50 bar of hydrogen at $65{ }^{\circ} \mathrm{C}$ for $3 \mathrm{~h}$ with a 0.033 mol\% of catalyst loading and in Me-THF as solvent, less than $5 \%$ conversion was achieved with phosphine diamine complex 1 and phosphine amino-amide complex 7 (entries 4 and 5). On the other hand, both phosphine amino-alcohol based complexes, $\mathbf{5}$ and 2, displayed similar performance achieving the conversion of ethyl acetate to ethanol with average TOF numbers of 242 and 212 respectively (entries 2 and 3). 
Table 3. Optimisation studies using $\mathrm{Ru}$ pre-catalysts for hydrogenation of ethyl acetate

\begin{tabular}{|c|c|c|c|c|c|c|}
\hline Entry & $\begin{array}{l}\text { Cat } \\
{[\mathrm{mol} \%]}\end{array}$ & $\begin{array}{l}\text { KOBut: } \\
\text { Cat }\end{array}$ & $\begin{array}{l}\text { Time } \\
\text { (h) }\end{array}$ & $\begin{array}{l}\mathrm{T} \\
(\mathrm{C})\end{array}$ & $\begin{array}{l}\text { Conv. }{ }^{[0]} \\
(\%)\end{array}$ & $\begin{array}{l}\text { TOF } \\
\left(\mathrm{h}^{-1}\right)\end{array}$ \\
\hline $1^{\lfloor a\rfloor}$ & 4 & $40: 1$ & 3 & 65 & 46 & 465 \\
\hline $2^{\lfloor a]}$ & 5 & $40: 1$ & 3 & 65 & 24 & 242 \\
\hline $3^{\lfloor a\rfloor}$ & 2 & $40: 1$ & 3 & 65 & 21 & 212 \\
\hline $4^{[a]}$ & 7 & $40: 1$ & 3 & 65 & 2 & 20 \\
\hline $5^{[a]}$ & 1 & $40: 1$ & 3 & 65 & 4 & 40 \\
\hline $6^{[\mathrm{b}]}$ & 4 & $40: 1$ & 1.5 & 75 & 40 & 808 \\
\hline $7^{[\mathrm{b}]}$ & 4 & $118: 1$ & 1.5 & 75 & 56 & 1131 \\
\hline $8^{[c]}$ & 4 & $118: 1$ & 1.5 & 75 & 71 & 1434 \\
\hline $9^{[c\rfloor\lfloor]}$ & 4 & $240: 1$ & 1.5 & 85 & 63 & 2470 \\
\hline $10^{[f]}$ & 4 & $118: 1$ & 1.5 & 75 & 28 & 566 \\
\hline $11^{[c]}$ & 5 & $118: 1$ & 1.5 & 75 & 37 & 748 \\
\hline
\end{tabular}

[a] The reactions were carried out using $0.033 \mathrm{~mol} \% \mathrm{Ru}$ catalyst and 1.3 mol\% of $t B u O K$, at an initial pressure of 50 bar using $7.7 \mathrm{mmol}$ of ethyl acetate in $3 \mathrm{ml}$ of Me-THF (general method A, ESI). [b] The reactions were carried out using $0.033 \mathrm{~mol} \% \mathrm{Ru}$ precatalyst, at an initial pressure of 50 bar using 30.7 $\mathrm{mmol}$ of ethyl acetate $(3 \mathrm{~mL}$ ) in $3 \mathrm{ml}$ of Me-THF (general method B, ESI). [c] Reactions were carried out in neat ethyl acetate, otherwise using conditions as in "[b]". [d] Ethanol produced determined by ${ }^{1} \mathrm{H}$-NMR using 1methylnaphthalene as internal standard. [e] $0.017 \mathrm{~mol} \%$ of catalyst and 3.9 mol\% of $t \mathrm{BuOK}$ used. [f] Reaction carried out at constant pressure of $15 \mathrm{bar}$ $\mathrm{H}_{2}$, otherwise as in "[b]".

Under the same mild conditions, the best performance was achieved by ruthenium PNN complex 4 (entry 1) with a conversion of $46 \%$ and an average TOF number of $465 \mathrm{~h}^{-1}$. We further investigated the activity of complex 4 using a 50 $\mathrm{mL}$ stainless steel glass lined autoclave. Using this vessel and increasing the temperature $10{ }^{\circ} \mathrm{C}$ to $75{ }^{\circ} \mathrm{C}$ doubles the conversion (entry 6). Increasing the base loading from $1.3 \mathrm{~mol} \%$ to $3.9 \mathrm{~mol} \%$ (base: catalyst ratio of 118) enhanced the performance of complex 4 producing ethanol with an average TOF number of $1131 \mathrm{~h}^{-1}$ (entry 7). The ester hydrogenation reaction can also be run in neat ethyl acetate without solvent, increasing further the reaction rate (entry 8 ). Complex 4 is also active at a lower catalyst loadings at $85^{\circ} \mathrm{C}$ (entry 9) giving a TOF of $2470 \mathrm{~h}^{-1}$ using an ester to catalyst loading of $0.017 \mathrm{~mol} \%$ with $3.9 \mathrm{~mol} \%$ of base. Lower pressures (15 bar) could be used in the hydrogenation of ethyl acetate although the TOF is reduced somewhat.

3-(Z)-Hexen-1-ol (leaf alcohol) occurs in the green parts of many plants and gives them the characteristic "green smell" odour. This molecule and other structural analogues are used in the perfumery industry to give a green note to fragances. This naturally occurring homoallylic alcohol is also frequently used in the flavors industry in minty, fruity and green herbal tea aromas. ${ }^{[9]}$ The reduction of the conjugated dienoate ethyl sorbate could be part of a very direct route to the fragrance molecule leaf alcohol involving a stereospecific 1,4-cis-hydrogenation of sorbic alcohol using $\left[\left(\mathrm{Cp}^{*}\right) \mathrm{Ru}(\mathrm{COD})\right]\left[\mathrm{BF}_{4}\right]$ type complexes to produce the mono-unsaturated alcohol with high selectivity. ${ }^{[9(\mathrm{a}), 9(\mathrm{c})]}$ However, the chemoselective ester hydrogenation of sorbate esters to unsaturated alcohols, has to our knowledge, never been achieved, and conjugated esters remain a challenge even for the most chemoselective catalysts. ${ }^{[(a), 10]}$ 


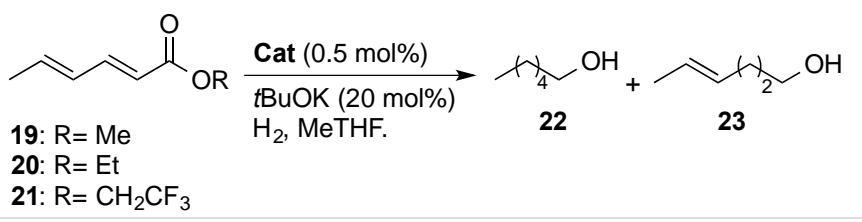

\begin{tabular}{|c|c|c|c|c|c|c|c|}
\hline Entry $^{[a]}$ & Ester & Cat & $\begin{array}{l}\mathrm{P} \\
\text { (bar) }\end{array}$ & $\mathrm{t}(\mathrm{h})$ & $\begin{array}{l}\mathrm{T} \\
\left({ }^{\circ} \mathrm{C}\right)\end{array}$ & $\begin{array}{l}\text { Conv. }^{[0]} \\
22(\%)\end{array}$ & $\begin{array}{l}\text { Conv. }^{\left[{ }^{10]}\right.} \\
\mathbf{2 3}(\%)\end{array}$ \\
\hline 1 & 19 & 4 & 50 & 21 & 65 & 67 & 33 \\
\hline 2 & 20 & 4 & 50 & 21 & 65 & 70 & 30 \\
\hline 3 & 21 & 4 & 50 & 21 & 65 & 58 & 15 \\
\hline 4 & 19 & 4 & 50 & 2 & 65 & 65 & 35 \\
\hline 5 & 20 & 4 & 50 & 2 & 65 & 62 & 38 \\
\hline 6 & 20 & 7 & 50 & 2 & 65 & 49 & 51 \\
\hline 7 & 20 & 2 & 50 & 2 & 65 & 65 & 35 \\
\hline 8 & 20 & 1 & 50 & 2 & 65 & 79 & 21 \\
\hline $9^{[c]}$ & 20 & 4 & 50 & 2 & 65 & 67 & 33 \\
\hline $10^{[c]}$ & 20 & 7 & 50 & 2 & 65 & 48 & 52 \\
\hline $11^{[c]}$ & 20 & 2 & 50 & 2 & 65 & 16 & 53 \\
\hline $12^{[\mathrm{d}]}$ & 20 & 7 & 50 & 2 & 65 & 39 & 61 \\
\hline $13^{[e]}$ & 20 & 7 & 50 & 2 & 65 & 20 & 80 \\
\hline 14 & 20 & 4 & 30 & 2 & 65 & 64 & 36 \\
\hline 15 & 20 & 7 & 30 & 2 & 65 & 54 & 46 \\
\hline 16 & 20 & 2 & 30 & 2 & 65 & 39 & 61 \\
\hline 17 & 20 & 4 & 50 & 2 & 50 & 25 & 37 \\
\hline 18 & 20 & 7 & 50 & 2 & 50 & 31 & 55 \\
\hline 19 & 20 & 2 & 50 & 2 & 50 & 33 & 67 \\
\hline 20 & 20 & 4 & 30 & 2 & 50 & 25 & 37 \\
\hline 21 & 20 & 7 & 30 & 2 & 50 & 31 & 55 \\
\hline 22 & 20 & 2 & 30 & 2 & 50 & 33 & 67 \\
\hline
\end{tabular}

[a] Unless otherwise stated, the reactions were carried out using $0.5 \mathrm{~mol} \%$ of cat, $t \mathrm{BuOK}$ as base $20 \mathrm{~mol} \%$ at an initial pressure of 50 bar using $1.0 \mathrm{mmol}$ of ester in $3 \mathrm{ml}$ of Me-THF. [b] Conversion determined by ${ }^{1} \mathrm{H}$ NMR using 1 methylnaphthalene as internal standard. [c] DMAP (1.5 mol\%) used as cocatalyst. [d] DBU (1.5 mol\%) used as co-catalyst. [e] $\mathrm{PPh}_{3}(1.5 \mathrm{~mol} \%)$ used as co-catalyst.

We attempted the hydrogenation of different sorbate esters in order to achieve a chemoselective reduction of the ester to produce sorbic alcohol (Table 4), but unfortunately sorbic alcohol was not observed under the reaction conditions used in this study. On the other hand, the monounsaturated alcohol 23, possibly interesting since other isomers of leaf alcohol also possess a similar type of odour, ${ }^{[9(b)]}$ could be obtained with moderate chemoselectivity. We first examined the influence of the ester moiety in the sorbate ester reduction using Ru catalyst 4 (entries 1-5). The reaction using commercially available ethyl sorbate 20 afforded the highest amount of $(E)$-hex-4-en-1-ol 23 with a $38 \%$ conversion (entry 5). Next, we examined the performance of some of the most active catalysts (entries 6-8). Phosphine-aminoamide catalyst 7 showed the higher selectivity towards 23 with a 51:49 selectivity (entry 6 ). The use of additives (entries 9-13) produced different results. Catalyst 7 , in the presence of 1.5 mol\% of DMAP as co-catalyst (entry 7 ) gave virtually no change in the the selectivity of the process, but the use of $\mathrm{PPh}_{3}$ as additive afforded compound 23 with a high $80 \%$ selectivity (entry 13). We also examined the effect of reducing pressure and temperature on the selectivity of the reaction. Reducing the pressure to 30 bar (entries 14-16), reducing the $T$ to $50 \stackrel{\circ}{ }$ (entries 17-19) or both (entries 20-22) 
had a different effect depending on the catalyst used in the reaction. In the case of complex 7 , the selectivity in the reaction was similar to that initially achieved under the initial reaction conditions (50 bar and $65{ }^{\circ} \mathrm{C}$ ).

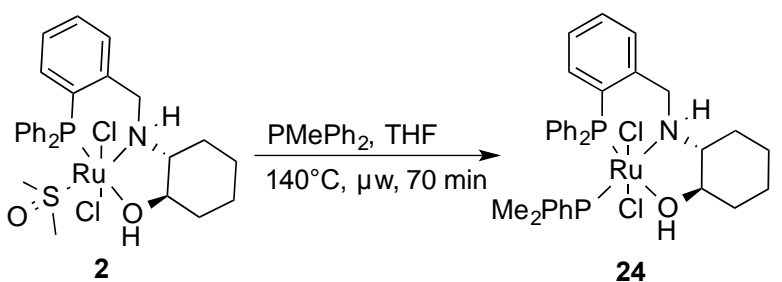

Scheme 1. DMSO substitution in Ru complex 2. 95\% conversion to product was obtained with $64 \%$ isolated yield of pure complex 24

The positive effect of adding a coordinating additive to the hydrogenation has been shown to improve chemoselectivity in some cases (Table 4, entries 6 and 13). It was thought that a variation of these catalysts, where the labile DMSO is replaced by a phosphine or DMAP, could lead to more chemoselective catalysts. We were not able to isolate any DMAP containing complex but we succeeded in the synthesis and isolation of the phosphine containing counterparts. The substitution of DMSO proved to be more energetically demanding than initially expected. ${ }^{[11]}$ The reaction of complex 2 with $\mathrm{PPh}_{3}$ even using forcing conditions (150 ${ }^{\circ} \mathrm{C}$ ) (see E.S.I), was very sluggish, affording the substitution complex only with $40 \%$ conversion. Next we examined the substitution of DMSO with $\mathrm{PPhMe}_{2}$. The smaller cone angle of this phosphine should facilitate the reaction. That was the case and the complex was prepared under the conditions shown in Scheme 1. The ${ }^{31} \mathrm{P}\left\{{ }^{1} \mathrm{H}\right\}$ NMR spectrum of $\mathbf{2 4}$ shows two characteristic groups of doublets at $\delta=62.4$ and 21.0 with $J_{P P}$ $=38.1 \mathrm{~Hz}$ corresponding to the two different phosphorus atoms. To determine unambiguously the structure of complex 24, an X-ray diffraction study was carried out. The X-ray structure of the complex is shown in Figure 6. The structure confirms that the DMSO ligand has in fact been replaced by $\mathrm{PPhMe}_{2}$. The coordination mode around the ruthenium atoms remains broadly the same than in complex 2, an octahedral ruthenium complex with the tridentate neutral PNO ligand and the two chlorine atoms in apical positions. When compared with its precursor 2, complex 24 has slightly longer $\mathrm{Ru}-\mathrm{N}$ and $\mathrm{Ru}-\mathrm{O}$ bond lengths (Figures 2 and 6 ), on the other hand the $\mathrm{Ru}-\mathrm{P}(1)$ bond is shorter, 2.239(1) vs 2.256(1) $\AA$ in complex 2. Both complexes also show similar $\mathrm{N}-\mathrm{Ru}-\mathrm{O}$ angles, 78.8(1) deg. vs 79.2(1) in complex 2.

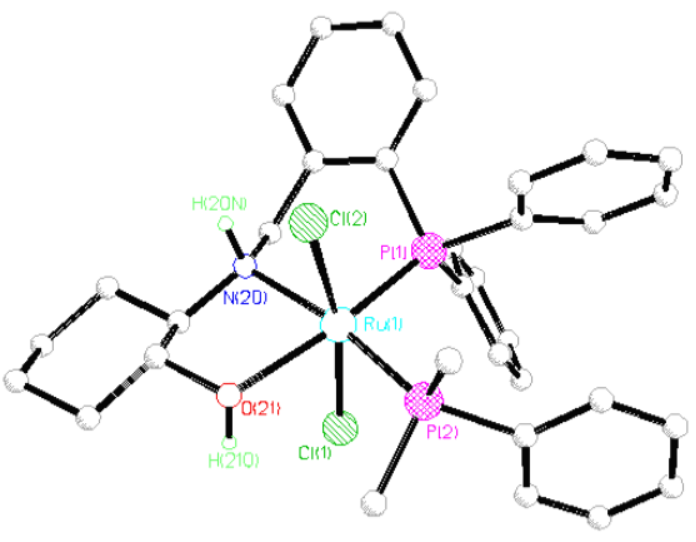

Figure 6. X-ray structure of complex 24. THF and hydrogen atoms (except $\mathrm{NH}$ and $\mathrm{OH}$ ) are omitted for clarity. Selected bond lengths $(\AA)$ and bond angles (deg): $\mathrm{Ru}-\mathrm{P}(1)=2.239(1), \mathrm{Ru}-\mathrm{P}(2)=2.278(1), \mathrm{Ru}-\mathrm{N}(20)=2.187(4), \mathrm{Ru}-\mathrm{O}(21)=2.236(4), \mathrm{O}(21)-\mathrm{Ru}-\mathrm{P}(1)=170.3(1), \mathrm{N}(20)-\mathrm{Ru}-$ $P(1)=92.0(1), O(21)-R u-P(2)=90.5(1), P(2)-R u-P(1)=98.89(4), N(20)-R u-O(21)=78.8(1)$. 


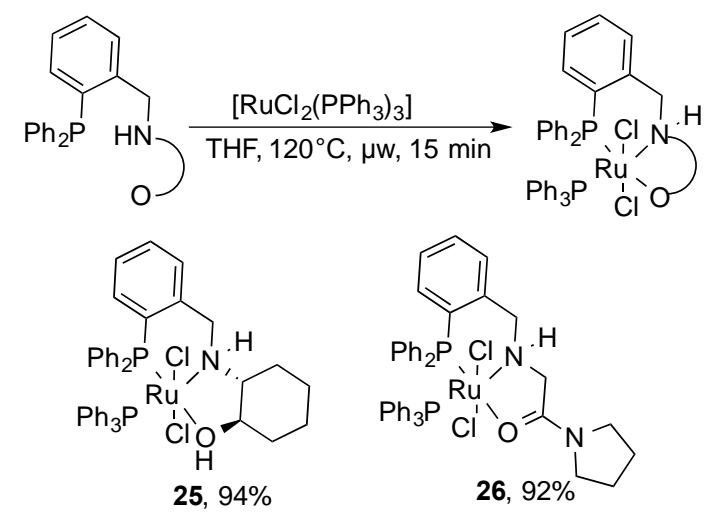

Scheme 2. Direct synthesis of complexes 25 and 26.

A direct synthesis involving the use of ligands (Scheme 2) and $\left[\mathrm{RuCl}_{2}\left(\mathrm{PPh}_{3}\right)_{3}\right]$ was also performed. Complexes 25 and 26 were prepared in $94 \%$ and $92 \%$ yield respectively. The ${ }^{31} \mathrm{P}\left\{{ }^{1} \mathrm{H}\right\}$ NMR spectrum of 25 and 26 shows the two characteristic groups of doublets corresponding to the two different phosphorus atoms in a similar way to those of complex 24 (see E.S.I.). These complexes were compared in a selection of ester hydrogenation reactions.

Table 5. Chemoselective reduction of esters in the presence of alkynes

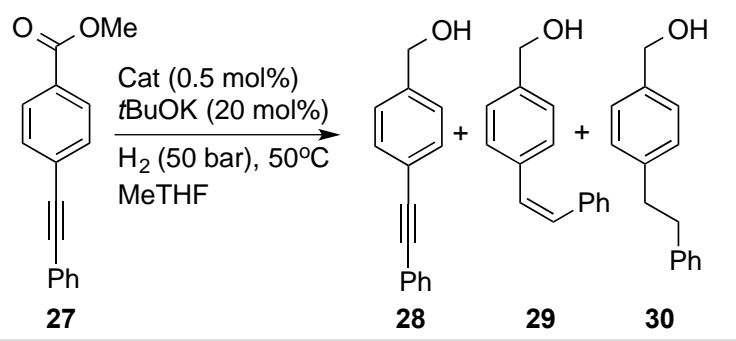

\begin{tabular}{lllllll}
\hline Ent. $^{[\mathrm{a}]}$ & Cat & $\mathrm{t}(\mathrm{h})$ & $\% \mathbf{2 7 ^ { [ 0 ] }}$ & $\% \mathbf{2 8 ^ { [ 0 ] }}$ & $\% \mathbf{2 9}^{[0]}$ & $\% \mathbf{3 0}^{[0]}$ \\
\hline $1^{[\mathrm{c}]}$ & $\mathbf{4}$ & 17 & 99 & 61 & 6 & 30 \\
$2^{[\mathrm{c}]}$ & $\mathbf{4}$ & 5 & 97 & 71 & 4 & 4 \\
$3^{[\mathrm{d}]}$ & $\mathbf{4}$ & 5 & 99 & 72 & 2 & 5 \\
$4^{[\mathrm{e}]}$ & $\mathbf{4}$ & 5 & 99 & 78 & 9 & 2 \\
$5^{[\mathrm{c}]}$ & $\mathbf{4}$ & 5 & 98 & $70[53]$ & 6 & 2 \\
$7^{[\mathrm{f}]}$ & $\mathbf{2 4}$ & 5 & 93 & 42 & 14 & 5 \\
$8^{[\mathrm{g}]}$ & $\mathbf{2 5}$ & 5 & 66 & 17 & 4 & 1 \\
$9^{[\mathrm{c}]}$ & $\mathbf{7}$ & 17 & 87 & 16 & 10 & 3 \\
$1^{\left[0^{[\mathrm{h}]}\right.}$ & $\mathbf{2 6}$ & 5 & 66 & 9 & 3 & 0 \\
\hline
\end{tabular}

[a] Reactions were carried out using $0.5 \mathrm{~mol} \% \mathrm{Ru}$ precatalyst, at an initial pressure of 50 bar at $50^{\circ} \mathrm{C}$ using $0.5 \mathrm{mmol}$ of alkyne in $1.5 \mathrm{ml}$ of Me-THF (general method A, ESI). [b] Determined by ${ }^{1} \mathrm{H}$-NMR using 1methylnaphthalene as internal standard, [isolated yield of pure 28]. [c] $\mathrm{PPh}_{3}$ was used as additive $(1 \mathrm{~mol} \%)$. [d] $\mathrm{PPh}_{3}$ was used as additive $(2 \mathrm{~mol} \%)$. [e] DMAP was used as additive (1 mol\%). [f] Methyl (Z)-4-styrylbenzoate $(21 \%)$, methyl 4-phenethylbenzoate (4\%). [g] Methyl (Z)-4-styrylbenzoate $(21 \%)$, methyl 4-phenethylbenzoate (8\%). [h] Methyl (Z)-4-styrylbenzoate (22\%), methyl 4-phenethylbenzoate (13\%). 
The chemoselective reduction of esters in the presence of alkynes is a challenging process with several possible products being formed in the reaction and to the best of our knowledge, no literature precedent. The main products obtained in these reductions, using methyl 4-(phenylethynyl)benzoate 27 as model substrate, are shown in Table 5. Other possible products such as methyl (Z)-4-styrylbenzoate and methyl 4-phenethylbenzoate would be detectable but were not observed in most cases. Compounds 28-30 are well known literature compounds and their formation can be detected by ${ }^{1} \mathrm{H}$ NMR. We decided to study the performance of the most active and selective catalysts in the presence of coordinating additives and the new phosphine containing $\mathrm{Ru}$ complexes 24-26 in the chemoselective reduction of compound 27. We initiated our study with complex 4 in the presence of $1 \mathrm{~mol} \%$ of $\mathrm{PPh}_{3}$ hoping that the presence of this phosphine could compete with the alkyne in the coordination with the metal and thus avoid the reduction of the latter (Table 5, entry 1). The reaction afforded a positive result; the alkyne formed from the selective reduction of the ester functionality (28) being the main product in the reaction (61\% conversion after $17 \mathrm{~h})$. The reaction also afforded a relative large amount of the fully reduced product (30). PNO Complexes 2 and 7 were also tested (entries 6 and 9) but their selectivity towards 28 was inferior. With all 3 pre-catalysts small amounts of alkene 29 (6-14\%) were detected. Reducing the reaction time to $5 \mathrm{~h}$ increased the selectivity towards alkyne $\mathbf{2 8}(71 \%)$ with a small amount of the fully reduced product being formed (4\%) (entry 2). Increasing the amount of $\mathrm{PPh}_{3}$ did not afford any noticeable effect in the reaction (entry 3). The use of DMAP as additive afforded similar results to those using $\mathrm{PPh}_{3}$ (entry 4). Remarkably, using complex 4 with no $\mathrm{PPh}_{3}$ present in the reaction media offered very similar chemoselectivity in the reaction (entry 5). We also tested pre-catalysts 24-26 incorporating an extra phosphine ligand, in the reduction of $\mathbf{2 7}$. The reaction proved to be very unselective towards the reduction of the ester moiety. These catalysts produced noticeable amounts of other products that were not observed before, like methyl (Z)-4-styrylbenzoate, the alkene obtained from the selective cisreduction of 27, and methyl 4-phenethylbenzoate, the product obtained from the full reduction of the alkyne moiety. Attempts to use complexes $\mathbf{2 4 - 2 6}$ in a cis-selective semihydrogenation of the alkyne led to significant amounts of the fully reduced alkane methyl 4-phenethylbenzoate so was not pursued further.

Table 6. Ru catalysed reduction of methyl hex-5-enoate

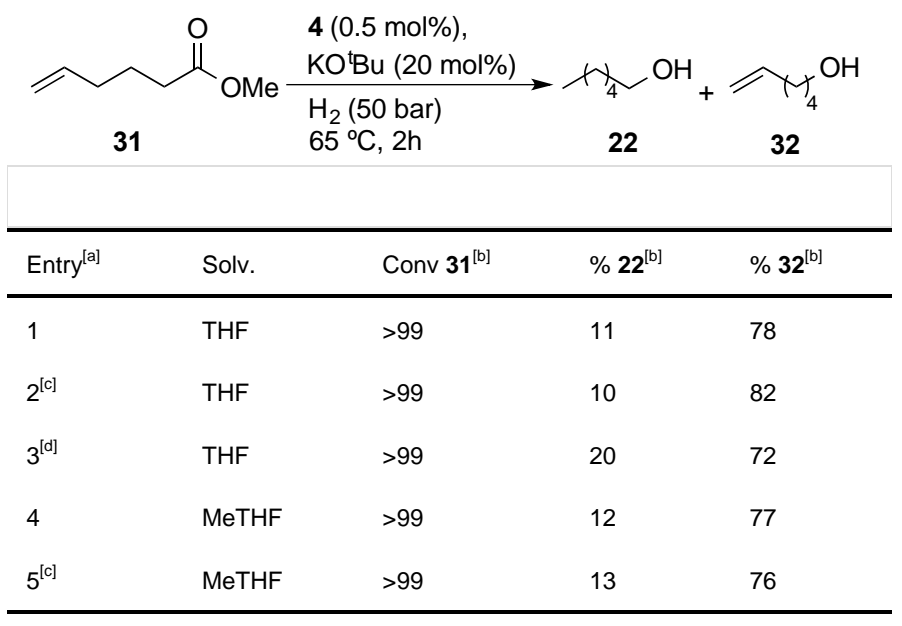

[a] Unless otherwise stated, reactions were carried out using $0.5 \mathrm{~mol} \%$ of cat, tBuOK as base $20 \mathrm{~mol} \%$, at an initial pressure of 50 bar using $0.5 \mathrm{mmol}$ of ester in $1.5 \mathrm{ml}$ of MeTHF. [b] Conversion determined by ${ }^{1} \mathrm{H}$ NMR using 1 methylnaphthalene as internal standard. Remaining balance is traces of isomerised internal alkene ester/alcohol. [c] DMAP was used as additive (1.5 mol\%). [d] $\mathrm{PPh}_{3}$ was used as additive (1.5 mol\%).

We also studied the reduction of an ester with a non-conjugated monosubstituted alkene moiety, methyl hex-5-enoate 31 (Table 6) using our best performing catalyst, complex 4 . Terminal alkene functionalised esters are more challenging substrates when compared with esters containing internal or more substituted alkenes, but less of a challenge than dienoates or $\alpha, \beta$ unsaturated esters. ${ }^{[(e)]}$ The reduction proceeded with full conversion in all cases under the reaction conditions shown in Table 6, affording a mixture of both the saturated and unsaturated alcohols. Catalyst $\mathbf{4}$ gave the unsaturated alcohol as major product in all cases. The introduction of DMAP as co-catalyst had a small beneficial effect in the chemoselectivity of the ester reduction with $\mathbf{4}$ affording unsaturated alcohol $\mathbf{2 5}$ with good chemoselectivity $(82 \%$, entry 2).

Complexes 25-26 were also tested in the reduction of methyl hex-5-enoate 31. These complexes did not promote a selective reduction of the ester and in all cases, hex-5-en-1-ol 32 was not observed. The hydrogenations afforded mixtures of the product obtained from the reduction of the terminal alkene, methyl hexanoate and the fully reduced hexanol 22, suggesting that the alkene reduction was actually promoted relative to the ester functionality under these reaction conditions. 
We also considered some other related applications for our catalysts. Recently, the fundamental reactivity of ester hydrogenation catalysts has been applied towards some interesting ideas for harnessing renewable feedstocks. ${ }^{[12]}$ We were attracted by the possibility of depolymerisation of oligomers and polymers. An exciting proof of concept paper ${ }^{[12(d)]}$ recently appeared in which the polyester polymer PET was depolymerised by hydrogenation to give 1,4-benzene dimethanol and ethylene glycol. This raises the possibility of a different mode of recycling: instead of melting PET and making off-white recycled polyesters, it could be recycled into chemicals that are otherwise derived from petrochemical resources. There is also a lot of PET that is currently not recycled, so this could be a good renewable feedstock. Only two examples using Milstein's catalysts are discussed in this initial work; the reactions were carried out at $160 \stackrel{\circ}{\circ} \mathrm{C}$ and using $2 \mathrm{~mol} \%$ of catalyst relative to repeat unit (or $1 \mathrm{~mol} \%$ relative to each ester). The publication of these results, that show that a step-change in reactivity would be needed prior to implementation, focused our studies on PET depolymerisation.

In order to identify the best catalyst and most suitable conditions and to study the effect of ethylene glycol production on the catalyst, we chose to study two model diesters first, 33a and 33b. The results are shown in Table 7 . It can be seen that once again, catalysts 4 emerges as the best catalyst for this transformation. More forcing conditions are required even for these soluble and simple substrates relative to the conditions used in the hydrogenation of other esters in this paper. In order to probe this, we carried out the hydrogenation of ester $\mathbf{8}$, but with varying amounts of ethylene glycol. The results (Scheme 3) show that ethylene glycol has a negative effect on the rate of this hydrogenation, at least at moderate temperatures.

Table 7. Ru catalysed reduction of diesters derived from ethylene glycol

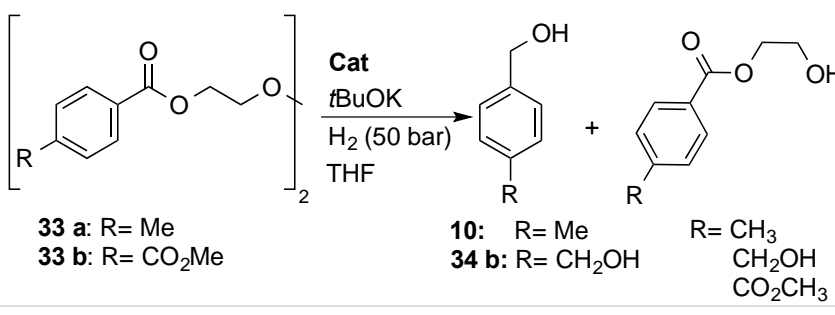

\begin{tabular}{|c|c|c|c|c|c|c|}
\hline Ent. & Sub. & $\begin{array}{l}\text { Cat } \\
\text { (mol\%) }\end{array}$ & $\begin{array}{l}\mathrm{T} \\
\left({ }^{\circ} \mathrm{C}\right)\end{array}$ & $\begin{array}{l}\mathrm{tBuO} \\
\mathrm{K}: \mathrm{Cat}\end{array}$ & $\begin{array}{l}\text { Conv. }^{[D]} \\
(\%)\end{array}$ & $\begin{array}{l}\%^{[b],[t]} \\
10 \text { or } 34 b^{[b]}\end{array}$ \\
\hline $1^{|a|}$ & $33 a$ & $4,[1.0]$ & 70 & $20: 1$ & $>99$ & $76^{[t]}$ \\
\hline $2^{\lfloor\mathrm{a}\rfloor}$ & $33 a$ & $5,[1.0]$ & 70 & $20: 1$ & $>99$ & $65^{\lfloor\rfloor\rfloor}$ \\
\hline $3^{\lfloor a]}$ & $33 a$ & $2,[1.0]$ & 70 & $20: 1$ & $>99$ & $60^{[t]}$ \\
\hline $4^{\lfloor\mathrm{a} \mid \mathrm{e}]}$ & $33 a$ & $7,[1.0]$ & 70 & $20: 1$ & $>99$ & $60^{[t]}$ \\
\hline $5^{\lfloor a]}$ & $33 a$ & $4,[0.5]$ & 70 & $40: 1$ & $>99$ & $>99$ \\
\hline $6^{[d]}$ & $33 a$ & $4,[1.0]$ & 110 & $20: 1$ & $>99$ & $>99$ [96] \\
\hline $7^{\mid \mathrm{a} \| \mathrm{c}]}$ & $33 \mathrm{~b}$ & $4,[2.0]$ & 100 & $10: 1$ & 82 & $73^{[t]}$ \\
\hline $8^{\lfloor a \mid[c]}$ & $33 \mathrm{~b}$ & $5,[2.0]$ & 100 & $10: 1$ & 37 & $8^{[t]}$ \\
\hline $9^{[a][c]}$ & $33 \mathrm{~b}$ & $2,[2.0]$ & 100 & $10: 1$ & 41 & $26^{[f]}$ \\
\hline $10^{[a][c]}$ & $33 \mathrm{~b}$ & $7,[2.0]$ & 100 & $10: 1$ & 32 & $15^{[f]}$ \\
\hline $11^{[\mathrm{a}] \mathrm{e}]}$ & $33 \mathrm{~b}$ & $4,[1.0]$ & 100 & $40: 1$ & 55 & $19^{[f]}$ \\
\hline $12^{[d]}$ & $33 \mathrm{~b}$ & 4. [2.0] & 110 & $10: 1$ & 88 & $74^{[f]}[71]$ \\
\hline
\end{tabular}

[a] Reactions were carried out at an initial pressure of 50 bar using $0.50 \mathrm{mmol}$ of dimer in $3.0 \mathrm{ml}$ of THF for $18 \mathrm{~h}$. [b] Determined by ${ }^{1} \mathrm{H}-\mathrm{NMR}$ using 1methylnaphthalene as internal standard, [isolated yield]. [c] Reaction carried out for 21 h. [d] Reaction carried out for 23 h. [e] 40:1 base to catalyst. [f] Remaining mass balance corresponds to partially reduced esters shown in the equation above. 


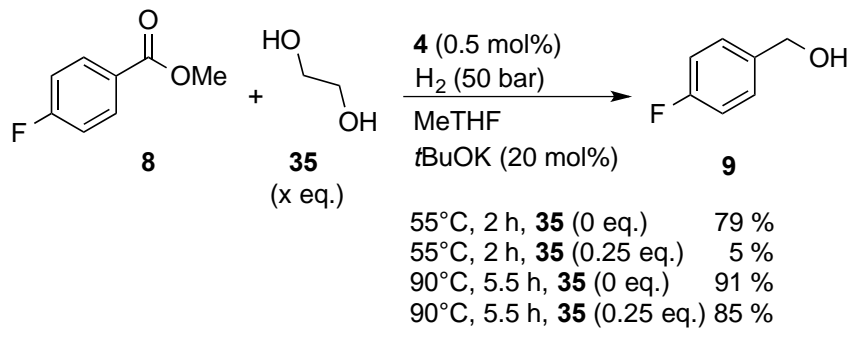

Scheme 3. Hydrogenation of ester 8 in the presence of ethylene glycol 35.

With 4 identified as the best catalyst, we studied the depolymerisation-hydrogenation of real samples of waste PET. In the hydrogenation of PET flakes (Table 8), we were pleased to find that at $110{ }^{\circ} \mathrm{C}$, very significant conversion to benzene dimethanol was obtained using $1 \mathrm{~mol} \%$ catalyst relative to each ester unit (entry 1 ). The reaction can be performed in toluene (entry 6), but the presence of anisole as co-solvent, as was used in ref 12(d), is needed in order to increase polymer solubility (entry 5). In common with almost every report on the use of catalysis on renewable substrates, the amount of catalyst used is likely to be significantly greater than the amounts that would be needed for research leading to implementation. The issue is such processes are generally producing relatively low value products, so catalyst (metal and ligand) cost is critical. Further studies on new catalysts to increase the productivity beyond this new benchmark are needed.

Table 8. Depolymerisation of poly(ethylene terephthalate) (PET)

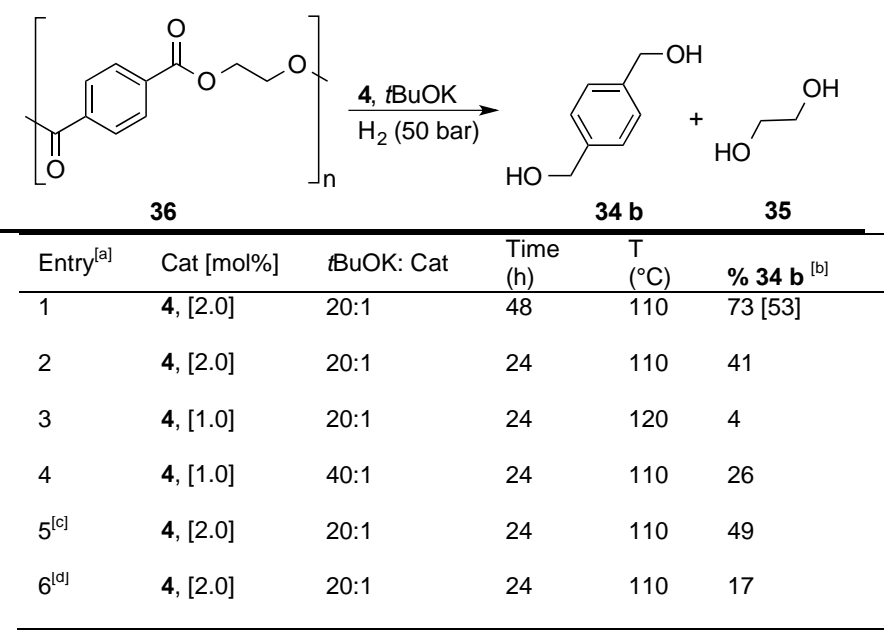

[a] Reactions were carried out at an initial pressure of 50 bar in a 50-50\% mixture of THF/Anisole. [b] Conversion determined by ${ }^{1} \mathrm{H}$-NMR using 1 methylnaphthalene as internal standard, [isolated yield]. [c] Reaction run in a $50-50 \%$ mixture of toluene/anisole. [d] Reaction run in toluene.

\section{Conclusions}

Ten different Ru complexes of phosphine-diamine, phosphine-amino-alcohol and phosphine-amino-amide ligands have been prepared and examined in the hydrogenation of a range of esters. The simple ethylene-diamine derived complex $\mathbf{4}$, emerges as significantly more active than the other catalysts. Complexes, $\mathbf{2}$ and $\mathbf{5}$, which are especially easy to prepare at significant scale, also give encouraging catalytic activity. The main focus here has been to establish how catalyst structure and substrate structure impact on the chemoselectivity of these ester hydrogenations; On this basis, complex 4 again outperforms other catalysts. In addition, the hydrogenation of ethyl acetate, carried out at larger scale, allow several conclusions to be made. The average turnover frequencies observed in neat ethyl acetate are rather high relative to some of the more complex substrates. This is promising in terms of future developments with this catalysts system towards commercially viable catalyst loadings for other hydrogenation. The extra high reactivity with this simple substrate ethyl acetate is partly that this is an easy, sterically unencumbered and very pure substrate, but also might relate to the high substrate concentrations used, since ketone hydrogenation using catalysts 4 was first order in 
substrate, and that is likely to be the case here. There is also strong pressure dependence. It is possible lower pressures could be used with a very efficiently stirred pressure vessel, but we have never been successful in carrying out ester hydrogenations at or near atmospheric pressure using these catalysts. Table 3, entries 7 and 10 show a significant increase in productivity when hydrogen pressure is increased from 15 to 50 bar pressure.

The effect of base co-catalyst certainly merits discussion. Previous studies showed us that this type of catalyst was nearly inactive at these quite low temperatures if base: catalyst ratios of 2:1 are used. Some activity was observed at $140 \stackrel{\circ}{\circ}$. A base-catalyst ratio of around $2: 1$ is actually optimum for highly enantioselective ketone hydrogenation using catalyst $1{ }^{[6]}$ In both the hydrogenation of para-fluorobenzoic acid methyl ester $\mathbf{8}$ and ethyl acetate, it can be seen that activity increases significantly when base: catalyst ratio is increased. This should perhaps be more formally when base concentration is increased, although we note experimentally that quite high concentrations were needed to observe any conversion under mild conditions for the benzoate 8 (table 1, entries 9 and 11), whereas in ethyl acetate hydrogenation, the absolute concentration of base [0.017 mol\% Ru cat, $3.9 \mathrm{~mol} \%$ base] is quite low even when average TOF are above $2000 \mathrm{~h}^{-1}$. Clearly there will be differences based on solvating medium, trace impurities in the substrate and the identity of the substrate. Recently, a revised mechanism has been put forward for the enantioselective hydrogenation of ketones using Noyori catalysts. ${ }^{[13]}$ We have previously found our catalysts to have some mechanistic similarities to Noyori catalysts, ${ }^{[6(c)]}$ so it seems reasonable that some of these insights might apply here. In particular, the revised mechanism postulates that the secondary alkoxide, produced after hydride transfer to a ketone, hydrogen- bonds to an $\mathrm{NH}$ function while deprotonating a dihydrogen ligand coordinated to $\mathrm{Ru}$. In ester hydrogenation, the initial product is a deprotonated hemi-acetal. Hemi-acetal anions are far less basic than simple alkoxides, so it may be the case that a higher concentration of base is needed either to facilitate the product deprotonating dihydrogen, or to directly deprotonate dihydrogen itself. An alternative or addition role that also requires more base than in ketone hydrogenation could be to assist the removal of bound hemi-acetal anion from ruthenium, or to assist catalyst stability. ${ }^{[14]}$ Catalyst 4 can be operated at relatively low amounts of base when catalyst loadings are low, but significant amounts do seem to be needed for high productivity. This also seems to be the case for other catalysts. The effect of DMAP is somewhat mysterious, since it does not seem to be in sufficient concentration to be simply acting as more base. It was designed to act as a co-ligand for $\mathrm{Ru}$ that would prevent $\mathrm{C}=\mathrm{C}$ bond coordination and subsequent reduction. However, we have not found it possible to make a DMAP complex in earlier studies and here we show that exchange of DMSO with phosphines is a difficult process, at least from the dichloride pre-catalysts. Moreover the phosphine-ligated Ru complexes 24-26 are actually not just poorly active catalysts but tend to reduce the $\mathrm{C}=\mathrm{C}$ bonds to a greater extent. $\mathrm{Ru} /$ BINAP/ DPEN catalysts have also been reported to fully reduce the $C=C$ bonds of cinnamate esters. Whether there is some outer sphere mechanism possible for $\mathrm{C}=\mathrm{C}$ reduction, or that unexpected and less saturated species form during hydrogenation is not clear. In any case, the use of catalyst $\mathbf{4}$ enables the ester hydrogenation in the presence of isolated double and triple bonds with good chemoselectivity. Catalyst $\mathbf{4}$ is therefore a useful ester hydrogenation catalyst and we have identified some structural features and experimental protocols that appear to be beneficial for chemo-selective and productive ester hydrogenation catalysis.

\section{Experimental Section}

Synthesis of ligands and catalysts along with their characterisation data can be found in the electronic supporting information.

\section{Hydrogenation of ethyl acetate using Ru catalysts}

Reactions were carried out using a Parr $50 \mathrm{~mL}$ stainless steel autoclave equipped with a pressure gage, gas inlet, safety valve and injection port equipped with rubber septum. A glass lined autoclave containing a magnetic stirring bar (crosshead) was charged with the appropriate amount of catalyst $(0.033 \mathrm{~mol} \%)$, purged with three vacuum/argon cycles and left under argon atmosphere. Ethyl acetate (30.7 mmol, $3.0 \mathrm{~mL})$, MeTHF $(3 \mathrm{~mL})$ and 1-methylnaphthalene $(0.2 \mathrm{~mL})$ as internal standard were added to the autoclave via the injection port using a syringe. Finally, potassium tert-butoxide (3.9 mol\%) (1 M solution in 2-methyl-2-propanol) (1.2 mmol, $1.2 \mathrm{~mL}$ ) was added. The autoclave was then purged three times with $\mathrm{H}_{2}$, pressurised to 50 bar and immersed into an oil bath preheated to the desired temperature. After the desired reaction time, the autoclave was cooled down to room temperature, the pressure slowly released and opened. A small sample was taken, diluted with $\mathrm{CDCl}_{3}$ and analysed by ${ }^{1} \mathrm{H} \mathrm{NMR}$ spectroscopy to calculate the conversion.

\section{Hydrogenation of methyl 4-(phenylethynyl)benzoate (27) using Ru catalysts}

A Biotage $5 \mathrm{ml}$ microwave vial containing a stirring bar was charged with catalyst $4(0.5 \mathrm{~mol} \%)$. The vial was sealed with a crimp cap, purged with three vacuum/argon cycles and left under argon atmosphere. The corresponding ester $(1.0 \mathrm{mmol}, 236 \mathrm{mg})$ was added using a syringe from a stock solution in Me-THF containing 1-methylnaphthalene as internal standard (3.0 mL). Finally, potassium tert-butoxide (20 mol\%) (1 M solution in 2-methyl-2-propanol) $(0.2 \mathrm{mmol}, 0.2 \mathrm{~mL})$ was added, then two needles were pierced into the vial and this was introduced into an autoclave, which had been previously purged with three vacuum/argon cycles. The autoclave was then purged three times with $\mathrm{H}_{2}$, pressurised to 50 bar and immersed into an oil bath preheated to the desired temperature. After the desired reaction time, the autoclave was cooled down to room temperature, the pressure slowly released and opened. A small sample was taken, diluted with $\mathrm{CDCl}_{3}$ and analysed by ${ }^{1} \mathrm{H}$ NMR spectroscopy to calculate the conversion. Purification by column chromatography on silica gel using petroleum ether:EtOAc 3:1 as eluent afforded (4-(phenylethynyl)phenyl)methanol 28 as a white solid (110 mg, $0.53 \mathrm{mmol}, 53 \%)$. 


\section{Depolymerisation of PET (36) using Ru catalyst 4}

A glass insert was charged with the appropriate amount of catalyst (1-2 mol \%) and substrate $(1 \mathrm{mmol})$ and was introduced into an autoclave, which had been previously purged with three vacuum/argon cycles. A round bottom flask was charged with 1-methyl naphthalene (approx. $0.08 \mathrm{~g}$ ) and quickly purged with three vacuum/argon cycles and left under argon atmosphere. THF ( $3 \mathrm{~mL}$ ), anisole $(3 \mathrm{~mL})$ and potassium tert-butoxide $(20 \mathrm{~mol} \%)(1 \mathrm{M}$ solution in 2-methyl-2-propanol) $(0.4 \mathrm{mmol}, 0.4 \mathrm{~mL})$ were added to the round bottom flask. The solution was then added to the autoclave and the autoclave was then purged three times with $\mathrm{H}_{2}$, pressurised to 50 bar and immersed into an oil bath preheated to the desired temperature. After the desired reaction time, the autoclave was cooled down to room temperature, the pressure slowly released and opened. A small sample was taken, diluted with $\mathrm{CDCl}_{3}$ and analysed by ${ }^{1} \mathrm{H}$ NMR spectroscopy to calculate the conversion. Purification by column chromatography on silica gel using EtOAc as eluent afforded 1,4benzene dimethanol $\mathbf{3 4} \mathbf{b}$ as a white solid $(73 \mathrm{mg}, 0.53 \mathrm{mmol}, 53 \%)$.

\section{Single-crystal X-ray structural determination}

CCDC-1049167 (2), -1049168 (4), -1049169 (6), -1049170 (7), and -1049171 (24) contain the supplementary crystallographic data for this paper. These data can be obtained free of charge from The Cambridge Crystallographic Data Centre via www.ccdc.cam.ac.uk/data\%5Frequest/cif.

\section{Acknowledgements}

The authors would like to thank the EPSRC National Mass Spectrometry Service, the EPSRC Impact Acceleration scheme for partial funding (with Johnson Matthey). Miss Katy Scott (University of St Andrews) is thanked for assistance with alkyne synthesis. Dr Mick O'Neill from Polymer Extrusion Technologies (UK) Ltd is thanked for kindly donating PET samples, and all the technical staff in the School of Chemistry are acknowledged for their assistance.

[1] (a) S. Nishimura in Handbook of Heterogeneous Catalytic Hydrogenation for Organic Synthesis, John Wiley and sons, New York, 2001, p 392. (b) A. B. Hungria, R. Raja, R. D. adams, B. Captain, J. Meurig Thomas, P. A. Midgley, V. Golovko, B. F. G. Johnson, Angew. Chem. Int. Ed. 2006, 45, 4782-4785; Angew. Chem. 2006, 118, 4900-4903 and refs therein.

[2] (a) H. T. Teunissen, C. J. Elsevier, Chem. Commun. 1998, 1367-1368. (b) H. T. Teunissen, C. J. Elsevier, Chem. Commun. 1997, 667-668.

[3] (a) S. Takebayashi, S. H. Bergens, Organometallics 2009, 28, 2349-2351. (b) J. Zhang, G. Leitus, Y. Ben-David, D. Milstein, Angew. Chem. Int. Ed, 2006, 45, 1113-1115; Angew. Chem. 2006, 118, 1131-1133. (c) E. Fogler, E. Balaraman, Y. Ben-David, G. Leitus, L. J. W. Shimon, D. Milstein, Organometallics 2011, 30, 3826-3833. (d) E. Balaraman, E. Fogler, D. Milstein, Chem. Commun, 2012, 48, 1111-1113. (e) L. A. Saudan, C. M. Saudan, C. Debieux, P. Wyss, Angew. Chem. Int. Ed. 2007, 46, 7473-7476; Angew. Chem. 2007, 119, 7617-7620. (f) Y. S. Sun, C. Koehler, R. Y. Tan, V. T. Annibale, D. T. Song, Chem. Commun, 2011, 47, 8349-8351. (g) W. Kuriyama, Y. Ino, O. Ogata, N. Sayo and T. Saito, Adv. Synth. Catal., 2010, 352, 92-96. (h) W. Kuriyama, T. Matsumoto, O. Ogata, Y. Ino, K. Aoki, S. Tanaka, K. Ishida, T. Kobayashi, N. Sayo, T. Saito, Org. Proc. Res. Dev. 2012, 16, 166-171. (j) W. W. N. O, A. J. Lough and R. H. Morris, Chem. Commun, 2010, 46, 8240-8242. (k) B. Boardman, M. J. Hanton, H. van Rensburg, R. P. Tooze, Chem. Commun., 2006, 2289-2291. (I) M. J. Hanton, S. Tin, B. Boardman, P. Miller, J. Mol. Catal. A-Chem. 2011, 346, 70-78. (m) S. Hitoshi, T. Kazunari, K. Haruhiko, (Mitsubishi Chem Ind.), 1996, US Pat. 5580991. (n) D. V. Tyers, M. Kilner, S. P. Crabtree, M. A. Wood, (Davy Process and Technology Ltd.), WO0309308. (o) C. Saudan, L. Saudan (Firmenich SA), 2010 (WO2010/061350. (p) L. Saudan, P. Dupau, J-J. Riedhauser, P. Wyss (Firmenich SA), 2010, US2010/0125144. (q) C. Saudan (Firmenich SA) WO2010/038209. (r) M. Ito, A. Sakaguchi, C. Kobayashi, T. Ikariya, J. Am. Chem. Soc. 2007, 129, 290-291. (s) S. Chakraborty, H. Dai, P. Bhattacharya, N. T. Fairweather, M. S. Gibson, J. A. Krause, H. Guan, J. Am. Chem. Soc. 2014, 136, 7869-7872. (t) D. Spasyuk, S. Smith, D. Gusev, Angew. Chem. Int. Ed. 2012, 51, 2772-2775; Angew. Chem. 2012, 124, 2826-2829. (u) D. Spasyuk, D. G. Gusev, Organometallics 2012 31, 5239-5242. (v) D. Spasyuk, S. Smith, D. Gusev, Angew. Chem. Int. Ed. 2013, 52, 2538-2542; Angew. Chem. 2013, 125, 2598-2602. (x) E. Fogler, J. A. Garg, P. Hu, G. Leitus, L. J. W. Shimon, D. Milstein, Chem. Eur. J. 2014, 20, 15727-15731. (y) T. Zell, Y. Ben-David, D. Milstein, Angew. Chem. Int. Ed. 2014, 53, 4685-4689. (z) F. A. Westerhaus, B. Wendt, A. Dumrath, G. Wienhofer, K. Junge, M. Beller, ChemSusChem 2013, 6, 1001-1005.

[4] M. L. Clarke, G. J. Roff in Handbook of Homogeneous Hydrogenation (Chap. 15), Ed. J. G. De Vries and C. J. Elsevier, Wiley-VCH, Weinheim, 2007, pp. 413-454.

[5] (a) S. Werkmeister, K. Junge, M. Beller, Org. Process Res. Dev. 2014, 18, 289-302. (b) M. L. Clarke, Synlett 2014, 25, 1371-1380. (c) M. L. Clarke, Catal. Sci. Technol. 2012, 2, 2418-2423. (d) L. A. Saudan in Sustainable Catalysis: Challenges and Practices for the Pharmaceutical and Fine Chemical Industries (Chapter 2), John Wiley and sons, New York, 2013, pp. 37-61. (e) P. A. Dub, T. Ikarija, ACS Catal. 2012, 2, 1718-1741.

[6] (a) M. L. Clarke, M. B. Diaz-Valenzuela, A. M. Z. Slawin, Organometallics 2007, 26, 16-19. (b) M. B. Diaz-Valenzuela, S. D. Phillips, M. B. France, M. E. Gunn, M. L. Clarke, Chem-Eur J, 2009, 15, 1227-1232. (c) S. D. Phillips, J. A. Fuentes, M. L. Clarke, Chem-Eur J. 2010, 16, 8002-8005. (d) S. D. Phillips, K. H. O. Andersson, N. Kann, M. T. Kuntz, M. B. France, P. Wawrzyniak, M. L. Clarke, Catal. Sci. Technol., 2011, 1, 1336-1339.

[7] I. Carpenter, S. C. Eckelmann, M. T. Kuntz, J. A. Fuentes, M. B. France, M. L Clarke, Dalton Trans. 2012, 41, 10136-10140.

[8] W. Baratta M. Ballico. A. del Zotto, K. Siega, S. Magnolia, P. Rigo, Chem. Eur. J. 2008, 14, 2557-2663.

[9] (a) P. Dupao, Top Organomet. Chem. 2012, 42, 47-64. (b) A. A. Vasiliev, G. V. Cherkaev, M. A. Nikitina, Chemistry and Computational Simulation. Butlerov Communications. 2003, 4, 33-43. C. (c) Fehr, I. Magpantay, M. Vuagnoux, P. Dupau, Chem. Eur. J. 2011, 17, 12571260.

[10] D. Spasyuk, C. Vivent, D. G. Gusev, J. Am. Chem. Soc. 2015, 3743-3746.

[11] P. Crochet, J. Gimeno, S. García-Granda, J. Borge, Organometallics 2001, 20, 4369-4377.

[12] (a) E. Balaraman, C. Gunanthan, J. Zhang, L. J. W. Shimon, D. Milstein, Nature chem. 2011, 3, 609-614. (b) M. R. L. Furst, R. Le Goff, D. Quinzler, S. Mecking, C. H. Botting, D. J. Cole-Hamilton, Green Chem. 2012, 14, 472-477. (c) N. M. Rezayaa, C. A. Huff, M. S. Sanford, J. Am. Chem. Soc. 2015, 137, 1028-1031. (d) E. M. Krall, T. W. Klein, R. J. Andersen, A. J. Nett, R. W. Glasgow, D. S. Reader, B. C. 
Dauphinais, S. P. Mc Llath, A. A. Fischer, M. J. Carney, D. J. Hudson, N. J. Robertson, Chem. Commun. 2014, 50, 4884-4887. (e) Z. Han, L. Rong, J. Wu, L. Zhang, Z. Wang, K. Ding, Angew chem. Int. Ed. 2012, 51, 13041-13045; Angew chem. 2012, 124, 13218-13222.

[13] P. A. Dub, N. J. Henson, R. L. Martin, J. C. Gordon, J. Am. Chem . Soc. 2014, 136, 3505-3521.

[14] S. Takebayashi, S. H. Bergens, Organometallics 2009, 28, 2349-2351. 
Figure 1. Ruthenium complexes of phosphine-diamine, phosphine-amino-alcohol and phosphine-amino-amide ligands used in this study.

Figure 2. X-ray structure of complex 2. Two acetonitrile molecules and hydrogen atoms (except $\mathrm{NH}$ and $\mathrm{OH}$ ) are omitted for clarity. Selected bond lengths $(\AA)$ and bond angles $(\mathrm{deg})$ : $\mathrm{Ru}-\mathrm{P}(1)=2.256(1), \mathrm{Ru}-\mathrm{N}(20)=2.151(5), \mathrm{Ru}-\mathrm{O}(21)=2.205(3), \mathrm{O}(21)-\mathrm{Ru}-\mathrm{P}(1)=171.31(9), \mathrm{N}(20)-\mathrm{Ru}-\mathrm{P}(1)$ $=92.3(1), \mathrm{N}(20)-\mathrm{Ru}-\mathrm{O}(21)=79.2(1)$.

Figure 3. X-ray structure of complex 4. One molecule of acetonitrile and hydrogen atoms (except $\mathrm{NH}$ and $\left.\mathrm{N} \mathrm{H}_{2}\right)$ are omitted for clarity. Selected bond lengths $(\AA)$ and bond angles (deg): $R u-P(1)=2.2806(7), R u-N(1)=2.130(2), R u-N(2)=2.164(2), N(2)-R u-P(1)=170.84(6), N(1)-R u-P(1)$ $=91.10(5), \mathrm{N}(1)-\mathrm{Ru}-\mathrm{N}(2)=79.89(7)$.

Figure 4. X-ray structure of complex 7. Hydrogen atoms (except $N H$ ) are omitted for clarity. Selected bond lengths $(\AA)$ and bond angles (deg): $\mathrm{Ru}-\mathrm{P}(1)=2.254(1), \mathrm{Ru}-\mathrm{N}(20)=2.152(4), \mathrm{Ru}-\mathrm{O}(2)=2.156(3), \mathrm{O}(2)-\mathrm{Ru}-\mathrm{P}(1)=170.66(9), \mathrm{N}(20)-\mathrm{Ru}-\mathrm{P}(1)=93.4(1), \mathrm{N}(20)-\mathrm{Ru}-\mathrm{O}(2)=77.2(1)$

Figure 5. X-ray structure of complex 6. Hydrogen atoms (except $\mathrm{NH}$ and $\mathrm{OH}$ ) are omitted for clarity. Selected bond lengths $(\AA)$ and bond angles $(\mathrm{deg}): \mathrm{Ru}-\mathrm{P}(1)=2.254(1), \mathrm{Ru}-\mathrm{N}(20)=2.200(4), \mathrm{Ru}-\mathrm{O}(22)=2.188(3), \mathrm{O}(22)-\mathrm{Ru}-\mathrm{P}(1)=175.5(1), \mathrm{N}(20)-\mathrm{Ru}-\mathrm{P}(1)=92.1(1), \mathrm{N}(20)-\mathrm{Ru}-\mathrm{O}(22)=$ 87.2(1)

Scheme 1. DMSO substitution in Ru complex 2. 95\% conversion to product was obtained with $64 \%$ isolated yield of pure complex $\mathbf{2 4}$

Figure 6. X-ray structure of complex 24. THF and hydrogen atoms (except $\mathrm{NH}$ and $\mathrm{OH}$ ) are omitted for clarity. Selected bond lengths $(\AA)$ and bond angles (deg): $R u-P(1)=2.239(1), R u-P(2)=2.278(1), R u-N(20)=2.187(4), R u-O(21)=2.236(4), O(21)-R u-P(1)=170.3(1), N(20)-R u-$ $P(1)=92.0(1), O(21)-R u-P(2)=90.5(1), P(2)-R u-P(1)=98.89(4), N(20)-R u-O(21)=78.8(1)$.

Scheme 2. Direct synthesis of complexes $\mathbf{2 5}$ and $\mathbf{2 6}$.

Scheme 3. Hydrogenation of ester 8 in the presence of ethylene glycol 35. 


\section{Layout 1:}

\section{FULL PAPER}

A simple catalyst for some difficult reductions: Ruthenium complexes of $\mathrm{P}, \mathrm{N}, \mathrm{N}$ and $\mathrm{P}, \mathrm{N}, \mathrm{O}$ ligands catalyse the reduction of esters with high activities. The Ru complex of the phosphinediamine shown in the scheme has been found to be a good catalysts for reducing alkene-, diene-, and alkyne functionalised esters, displaying good activity and chemoselectivity. This catalyst was also active in the hydrogenation of waste PET.

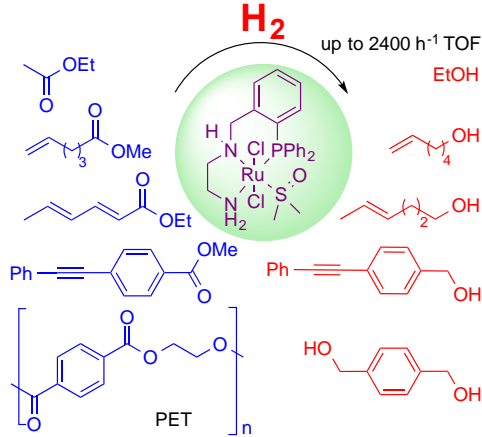

José A. Fuentes, Samuel M. Smith, M. Theresa Scharbert, Ian Carpenter, David B. Cordes, Alexandra M. Z. Slawin, and Matthew L Clarke*

Page No. - Page No.

On the functional group tolerance of ester hydrogenation and polyester depolymerisation catalysed by ruthenium complexes of phosphinediamine, phosphine-amino-alcohol and phosphine-amino-amide ligands.

Keywords: ruthenium $\bullet$ hydrogenation $\bullet$ depolymerisation $\bullet$ tridentate ligand $\bullet$ bifunctional catalysis 